\title{
Rare evidence for 'gnawing-like' behavior in a small-bodied theropod dinosaur
}

\author{
Caleb M Brown ${ }^{\text {Corresp., } 1}$, Darren H Tanke ${ }^{1}$, David W. E. Hone ${ }^{2}$ \\ ${ }^{1}$ Royal Tyrrell Museum of Palaeontology, Drumheller, Alberta, Canada \\ 2 School of Biological and Chemical Sciences, Queen Mary University of London, London, United Kingdom \\ Corresponding Author: Caleb M Brown \\ Email address: caleb.brown@mail.utoronto.ca
}

Mammalian carnivores show a higher degree of prey bone utilization relative to non-avian theropod dinosaurs, with this major ecological difference reflected in the frequency and morphology of tooth marks in modern and Cenozoic assemblage relative to Mesozoic ones. As such, prey bone utilization (i.e., gnawing, bone-breaking, osteophagy) may represent a key ecological strategy repeatedly exploited by mammalian carnivores but rarely in theropod dinosaurs. Here we described an isolated adult-sized hadrosaurid pedal ungual (III-4) from the Dinosaur Park Formation (Campanian) of southern Alberta which shows a unique pattern of bite marks from a small- to medium-sized theropod dinosaur. Thirteen distinct tooth marks occur in a restricted area of the ungual, and the pattern suggests up to six repeated, high-power bites delivered to the bone. The tracemaker cannot be definitively identified, but was likely a dromaeosaurid or very young tyrannosaurid. Tooth marks on at least four other Dinosaur Park Formation hadrosaur pedal unguals are reported, but the overall frequency of occurrence in unguals $(<1 \%)$ is much lower than that reported for other bones. The pattern of tooth marks on this specimen deviates from most described theropods tooth marks, and given the low volume of meat associated with the ungual, may represent theropod prey bone utilization as part of late-stage carcass consumption, and a behavior similar to mammalian gnawing. 
1

2 Rare evidence for 'gnawing-like' behavior in a small3 bodied theropod dinosaur

6 Caleb M. Brown ${ }^{1}$, Darren H. Tanke ${ }^{1}$, David W. E. Hone ${ }^{2}$

7

$8 \quad{ }^{1}$ Royal Tyrrell Museum of Palaeontology, Drumheller, Alberta, Canada

$9{ }^{2}$ School of Biological and Chemical Sciences, Queen Mary University of London, London, UK 10

11 Corresponding Author:

12 Caleb M. Brown

13 PO Box 7500, Drumheller, Alberta, Canada, T0J 0Y0

14 Email address: caleb.brown@gov.ab.ca 


\section{Abstract}

Mammalian carnivores show a higher degree of prey bone utilization relative to nonavian theropod dinosaurs, with this major ecological difference reflected in the frequency and morphology of tooth marks in modern and Cenozoic assemblage relative to Mesozoic ones. As such, prey bone utilization (i.e., gnawing, bone-breaking, osteophagy) may represent a key ecological strategy repeatedly exploited by mammalian carnivores but rarely in theropod dinosaurs. Here we described an isolated adult-sized hadrosaurid pedal ungual (III-4) from the Dinosaur Park Formation (Campanian) of southern Alberta which shows a unique pattern of bite marks from a small- to medium-sized theropod dinosaur. Thirteen distinct tooth marks occur in a restricted area of the ungual, and the pattern suggests up to six repeated, high-power bites delivered to the bone. The tracemaker cannot be definitively identified, but was likely a dromaeosaurid or very young tyrannosaurid. Tooth marks on at least four other Dinosaur Park Formation hadrosaur pedal unguals are reported, but the overall frequency of occurrence in unguals $(<1 \%)$ is much lower than that reported for other bones. The pattern of tooth marks on this specimen deviates from most described theropods tooth marks, and given the low volume of meat associated with the ungual, may represent theropod prey bone utilization as part of latestage carcass consumption, and a behavior similar to mammalian gnawing.

\section{Introduction}

A major ecological and feeding behavior distinction between Mesozoic non-avian theropod and modern and Cenozoic mammalian carnivores is the difference in utilization of prey bones as a food source (Fiorillo 1991). Both modern and fossil carnivorous mammalian species have been shown to make extensive use of prey bones as a dietary source (Kruuk 1972; Haynes 1980; Van Valkenburgh 1996). This is often characterized by repeated, high-power bites to bone extremities by premolars and molars, often for the purpose of exposing the lipid and nutrient rich marrow (Van Valkenburgh 1996; Van Valkenburgh 2007). This behavior may be considered 'gnawing', in that it follows the definition 'to bite or chew something repeatedly, usually making a hole in it or gradually destroying it' (Cambridge Dictionary 2016). This gnawing behavior is also often taxon and season specific, allowing for ecological inference based of gnawing damage (Haynes 1980; Haynes 1983). Indeed, bone-cracking is a specialized ecological strategy that has evolved several times within Carnivora (Van Valkenburgh 2007; Tseng 2013). While this gnawing behavior is most well-established in mammals - most commonly in orders Carnivora and Rodentia - this behavior may be present in other taxa as well.

In contrast to the pattern in Recent and Cenozoic mammals, most research on Mesozoic theropod dinosaurs has suggested that prey bone utilization in non-avian theropods is limited, with little direct evidence in the way of gnawing behavior (Fiorillo 1991; Chure et al. 1998; Jacobsen 1998; Hone \& Rauhut 2010). Patterns of tooth mark occurrence within Mesozoic assemblages support this interpretation in multiple ways. Firstly, relative to Recent and Cenozoic bone assemblages, there is a distinctly lower frequency of tooth marks in Mesozoic systems (Fiorillo 1991; Hone \& Rauhut 2010). Additionally, these tooth-marked bone assemblages are 
57 dominated by scratch/scrape marks that do not penetrate the bone cortex, relative to puncture
58 marks, suggesting these tooth-bone contacts are incidentally delivered while feeding on the

58

59

60

61

62

63

64

65

66

67

68

69

70

71

72

73

74

75

76

77

78

79

80

81

82

83

84

85

86

87

88

89

90

91

92

93

94

95 surrounding soft tissue (Hone \& Rauhut 2010). Finally, documented instances of theropod tooth marks can generally be characterized by a single bite, inflicting either scratches or punctures to the bone, but not repeated bites in a restricted area (Chure et al. 1998; Hone \& Rauhut 2010). This suggests that prey bone utilization (i.e., gnawing, bone-breaking, osteophagy) is a key ecological strategy that was, and is, repeatedly exploited by mammalian carnivores, but not theropod dinosaurs (Hone \& Rauhut 2010).

A possible exception of this pattern is in the Tyrannosauridae where osteophagy may have been possible due to a combination of a strong bite and large, robust teeth (Hurum \& Currie 2000; Hone \& Rauhut 2010; Gignac \& Erickson 2017). Despite this, direct evidence consistent with repeated biting on bones is rare (Erickson \& Olson 1996; Hone \& Watabe 2010; Dalman \& Lucas 2021), with the isolated, raking, and likely incidental marks dominating the tyrannosaur toothmark record. Putative tyrannosaur coprolites have demonstrated a high volume of consumed bone on occasion (Chin et al. 1998; Chin et al. 2003), though this may be more consistent with ingestion of intact portions of smaller prey animals.

Here we report an isolated hadrosaurid pedal ungual that shows strong evidence for repeated, powerful (i.e., sufficient enough to penetrate much of the bone cortex), and localized biting behavior in a small to medium-sized theropod dinosaur. The pattern of tooth marks is inconsistent with incidental contact, and rather, is a rare case of gnawing or 'gnawing-like' behavior in theropod dinosaurs.

\section{Materials \& Methods}

The specimen, TM) 2018.012.0123 (Royal Tyrrell Museum of Palaeontology), is an isolated hadrosaurid pedal ungual, collected from Bonebed 50 (specifically, Bonebed 50 east) in the core area of Dinosaur Provincial Park, Alberta. The specimen was found as part of the Queen Mary University of London - Royal Tyrrell Museum of Palaeontology field school in 2018, and collected under Research and Collection Permit 18-510 (Alberta Tourism, Parks and Recreation) and permit to Excavate Palaeontological Resources 18-019 (Alberta Culture and Tourism).

Bonebed 50 is a mixed (macrofossil-microfossil) multitaxic bonebed in the lower to middle portion of the Dinosaur Park Formation, $\sim 19 \mathrm{~m}$ above the contact the underlying Oldman Formation. This site consists of a series of stacked palaeochannel sandstones, the basal lags of each hosting a high diversity and abundance of microvertebrate fossil, as well as disarticulated to partially articulated adult hadrosaur skeletons, including the type of Corythosaurus excavatus (Tanke \& Russell 2012; Bramble et al. 2017), and isolated hatchling-to-nestling sized hadrosaur elements (Tanke \& Brett-Surman 2001; Eberth \& Evans 2011). Although at least three associated to articulated adult hadrosaur skeletons are known from this site, the ungual cannot be confidently associated with any of these, and likely represents an isolated specimen within the macrovertebrate component of the bonebed.

PeerJ reviewing PDF | (2021:02:57752:1:1:NEW 21 Apr 2021) 
96

97

98

99

100

101

102

103

104

105

106

107

108

109

110

111

112

113

114

115

116

117

118

119

120

121

122

123

124

125

126

127

128

129

130

131

132

133

134

135

The ungual was almost completely encrusted with a soft to medium-hardness iron-rich siltstone. An airscribe on a low setting was gently used to remove most of this and a scalpel was used to remove the rest. The rock separated cleanly from the bone. An air abrasive on low air pressure and powder (sodium bicarbonate) flow settings was used as a final cleaning, followed by water and toothbrush. No adhesive, consolidant, or surface coat were applied.

Specimen photography was performed with a Canon EOS 6D (50 mm [1:1.4) and 24$105 \mathrm{~mm}[1: 4]$ lenses). Ammonium chloride powder coating was used with photography to enhance the surface texture while homogenizing bone colour. Ammonium chloride was applied using the "dry method" sensu Parsley and colleagues (2018). All measurements were taken with digital calipers $(150 \mathrm{~cm})$ to the nearest tenth of a millimeter. Figures were prepared using Adobe Illustrator (V. 15.1.0) and Adobe Photoshop (V. 12.1).

Statistical test we performed in the R programing language (Team 2009) using the functions ks.test (stats), and chisq.test (stats), while the histograms were created using the function hist (graphics), lines (graphics) and density (stats). Chi-squared tests were used to compare the frequency of tooth marks between different skeletal elements (i.e., hadrosaur unguals to hadrosaur metapodials, hadrosaur unguals to all other hadrosaur elements). To see if the inter-tooth spacing of potential tracemakers were different from that of the the inter-mark spacing on the ungual, Kolmogorov-Smirnov tests (two sample) were used to test if these were drawn from a common size distribution.

\section{Results}

Description - The specimen is complete, missing only abraded portions of the cortical bone along its extremities, particularly on the rim of the articular facet (Fig. 1A). The ungual measures $105 \mathrm{~mm}$ in proximodistal length, $99 \mathrm{~mm}$ in maximum transverse width, and $49 \mathrm{~mm}$ it maximum height. The proximal articular face is $49 \mathrm{~mm}$ tall and $79 \mathrm{~mm}$ wide. The morphology and symmetry of the ungual indicates that it derives from digit three (i.e., III-4), the central and largest of the pedal digits (Zheng et al. 2011), and the largest ungual (Fig. 2A), although whether it is from the left or right side is unclear. Given that the specimen is equivalent in size, or larger than, specimens regarded as adults of contemporaneous hadrosaurid species (i.e., Gryposaurus, Corythosaurus), it likely pertained to an adult-sized individual (Parks 1920).

A series of prominent tooth marks (observed in the field prior to collection) are present on the ventral (plantar) surface of the ungual, but no marks are seen of the dorsal or articular surface (Fig. 1A, B). A restricted area, $\sim 30 \times 20 \mathrm{~mm}$, on one-half of the ventral surface adjacent to the articular facet bears 13 distinct tooth marks (Fig. 2B). The largest tooth mark is $10.5 \mathrm{~mm}$ long, and $3.3 \mathrm{~mm}$ wide, while the smallest is $2.7 \mathrm{~mm}$ long and $1.6 \mathrm{~mm}$ wide (Table 1). The majority of the tooth marks are approximately three times longer than wide, but the smallest are more equidimensional. The morphology of the tooth marks is somewhat intermediate between the elongate v-cross section furrows, and the circular to ovoid pits that have previously been described for theropod tooth marks (Erickson \& Olson 1996; Jacobsen 1998). Although prominent, the marks are shallow, with the deepest marks around $1 \mathrm{~mm}$ in depth. The marks 
136 penetrate the smooth surface of the cortical bone, and exposed the underling anteroposteriorly

137

138

139

140

141

142

143

144

145

146

147

148

149

150

151

152

153

154

155

156

157

158

159

160

161

162

163

164

165

166

167

168

169

170

171

172

173

174

oriented cancellous bone fibers. Individual marks are numbered using Arabic numerals (Fig. 2C).

Relative to each other, the marks are not random in orientation or position. The long axis of all tooth marks is parallel, running $\sim 20^{\circ}$ to the transverse axis of the digit (Fig. 1A, 2B). Further, the marks are positioned in an approximate grid pattern, being aligned in two nearly perpendicular axes (Fig. 2C). The long axes of the marks are nearly aligned with one of these grid axes (oriented distomedially) termed rows (labeled with roman numerals), and lie nearly perpendicular to the other (oriented distolaterally) termed columns (labeled with lowercase letters) (Fig. 2C). All tooth marks, with the exception of mark number 11, fit this discrete gridlike pattern. There are three columns (a-c) and at least four, but possibly up to six rows (i-vi). Tooth mark spacing (based on midpoints) between successive marks within rows varies from 4.9 to $8.8 \mathrm{~mm}$, with a mean of $7.0 \mathrm{~mm}$, while spacing between successive marks in columns is smaller, from 4.0 to $7.4 \mathrm{~mm}$ with a mean of $5.3 \mathrm{~mm}$ (Table 2). The bone surface on which the marks occur is slightly convex along a transverse transect. In contrast an orthogonal proximodistal transect the surface show more topographic variation, and specifically is strongly concave at the distolateral extreme of the element.

Frequency of tooth marks on unguals - Despite the apparent oddity of bite marks to a hadrosaur ungual, TMP 2018.012.0123 is not an isolated occurrence. A second hadrosaur pedal ungual from the Dinosaur Park Formation, UALVP 55092 (University of Alberta Laboratory of Vertebrate Paleontology), appears to shows a cluster of three distinct tooth marks on the ventral (plantar) portion of the ungual, oriented at $\sim 45^{\circ}$ to the long axis of the ungual (Fig. 3A). In this second case, the marks appear to be a series of three parallel shallow furrows consistent with a single bite, and more in line with other described theropod feeding traces.

Given that two Dinosaur Park Formation hadrosaur unguals show unexpected bitemarks, a survey was undertaken to determine if this is a more common, but previously unrecognized, pattern. A total of 425 isolated hadrosaurid unguals (pedal and manual) from the Dinosaur Park and Oldman formations across southern Alberta, were specifically examined for tooth marks (Supplemental Table S1). Only two cases of definitive tooth marks were found within this sample (Fig. 3B, C), suggesting the frequency of tooth marks on hadrosaur unguals is very low $(<1 \%)$. This is significantly lower than the reported frequency of tooth marks on both overall hadrosaurid bones, 14\% (47/339), and hadrosaur metapodials, 13\% (16/120), from this formation (chi-square $=54.152$ and 44.535, $\mathrm{p}=1.856 \mathrm{e}-13$ and 2.499e-11, respectively) (Jacobsen 1998).

These two other tooth marked unguals are smaller than TMP 2018.012.0123, and, as with UALVP 55092, the marks are clusters of parallel (or nearly parallel) elongate furrows oriented at $\sim 45^{\circ}$ to the long axis of the ungual. The first of these specimens, TMP 1979.008.0769 (II-3?), is $59 \mathrm{~mm}$ wide and $74 \mathrm{~mm}$ long, and preserves four tooth marks (11.0, 23.4, 25.1, and $10.9 \mathrm{~mm}$ in length) on the dorsolateral surface with inter-mark spacing of around $3.5 \mathrm{~mm}$ (Fig. 3B). The second specimen, TMP 1980.016.1215 (III-4), is $59 \mathrm{~mm}$ wide and $64 \mathrm{~mm}$ long (estimate), and also preserves four tooth marks $(9.4,7.5,26.7,8.1 \mathrm{~mm}$ in length) on the dorsal surface with

PeerJ reviewing PDF | (2021:02:57752:1:1:NEW 21 Apr 2021) 
175 inter-mark spacing of around $5.2 \mathrm{~mm}$ (Fig. 3C). In all four cases, marks are seen one on side of 176 the ungual and not the other.

177 The frequency of tooth marks in non-ungual phalanges may be higher than for unguals, as

178 several cases are known and have been reported for both hadrosaurid - TMP 1966.011.0022

179 (Jacobsen 1998), TMP 1981.023.0011 (Jacobsen 1998), TMP 1993.110.0003, TMP

180 2016.012.0096, TMP 2019.014.0004, UCMP 140601, (Erickson \& Olson 1996) - and

181 tyrannosaurid - UCMP 137538, MOR 1126 elements (Longrich et al. 2010). An allosaur pedal

182 ungual with allosaur toothmarks has also been recently reported (Drumheller et al. 2020).

183

\section{Discussion}

185 Pattern of toothmarks - In total 13 distinct tooth marks are preserved on TMP 2018.012.0123, 186 but their alignment in a grid-like pattern suggests these were the result of a combination of

187

188

189

190

191

192

193

194

195

196

197

198

199

200

201

202

203

204

205

206

207

208

209

210

211

212

213

214 successive teeth in the toothrow making contact with the bone surface, and the tooth row moving laterally relative to the ungual between successive bites.

Given the alignment of the mark long axes, the relatively consistent within-row mark spacing, and the saddle shaped bone surface, it is likely that the rows (e.g., i, ii, iii etc.) represent individual bites, with successive teeth in the tooth row making aligned marks (Fig. 2C). The multiple rows represent the bone being moved laterally relative to the tooth row (or vice versa) between successive bites. The individual marks within columns (e.g., a, b, c) therefore are interpreted as the same tooth making contact with the bone surface multiple times as the bone slid laterally relative to the tooth row between bites. Under this hypothesis there are up to three successive teeth in the tooth row that make contact with the bone, and a minimum of four, and possibly up to six, distinct bites. The relatively equal spacing between the successive bites (i.e., rows $\mathrm{i}-\mathrm{iv}$ ) indicate that the relative change in the position of the bone to the teeth differed by consistent distance between each successive bite, $\sim 5 \mathrm{~mm}$. Under this hypothesis, the average distance between successive teeth in the toothrow is $7.0 \mathrm{~mm}$. A slightly different hypothesis is illustrated if the long axis of the marks, rather than the position of the marks, are used as the primary alignments (Fig. 2D). Under this hypothesis lines illustrating possible tooth marks aligned in the toothrow are indicated. For this hypothesis, marks caused by successive teeth, and therefore the spacing between them, are less obvious to establish, but are roughly similar to that of the scenario above.

It is possible, though in our mind less likely, that the interpretation of these axes may be swapped. In this case, the columns (e.g., a, b, etc.) represent successive teeth in the toothrow making contact in a single bite, while the rows (e.g., i, ii, etc.) represent repositioning and lateral movement of the bone between successive bites. Under this hypothesis there are up to five successive teeth (with a potential one-tooth gap) in the tooth row that make contact with the bone, and only three distinct bites. Under this hypothesis, the average distance between successive teeth in the toothrow is much smaller at $5.3 \mathrm{~mm}$. Movement of the teeth across the bone surface during the bite in this hypothesis would be nearly orthogonal to the cross-sectional long axis of the tooth.

PeerJ reviewing PDF | (2021:02:57752:1:1:NEW 21 Apr 2021) 
215

216

217

218

219

220

221

222

223

224

225

226

227

228

229

230

231

232

233

234

235

236

237

238

239

240

241

242

243

244

245

246

247

248

249

250

251

252

253

Several lines of evidence support the former interpretation relative to the later. The relative size and shape of the marks is more consistent within columns (e.g., marks 1, 4, 7) than within rows (e.g., marks 3, 4, 5). The spacing between successive marks is more consistent within rows, than within columns. The movement orthogonal to the cross-sectional long axis of the tooth would also increase the chance of tooth damage (see Hone \& Chure 2018). Finally, the bone surface transected by the rows (i.e., i, ii) is gently convex, with the bites located at the high point of the transect. Conversely the bone surface transected by the columns (i.e., a, b) has a higher amplitude topography, is broadly concave, and bounded proximally and distally by bone surfaces that are above the level of the tooth marks, but that are not marked.

Regardless of which of these biting scenarios is correct, a series of closely spaced powerful bites were delivered to the ungual with the element repositioned relative to the tooth row between successive bites.

Tracemaker - The tracemaker responsible for the toothmarks can be narrowed down to a relatively small number of candidates. The various non-dinosaurian carnivores present in the Dinosaur Park Formation assemblage, including mammals, crocodylians and squamates, can be ruled out - see similar discussion in (Hone et al. 2018). Gnawing marks thought to derive from mammalian trace makers have been described from the Belly River Group, and these broadly resemble gnaw marks of modern rodents (Longrich \& Ryan 2010). The bite marks of both modern and Cretaceous crocodylians leave characteristic deep, circular to sub-circular punctures (Njau \& Blumenschine 2006; Noto et al. 2012; Boyd et al. 2013; Botfalvai et al. 2014;

Drumheller \& Brochu 2014) distinct from those seen on TMP 2018.012.0123. Although furrows with V-shaped cross-sections can be produced by crocodylian teeth (Njau \& Blumenschine 2006), these are neither characteristic nor diagnostic of this group. They are also often continuous with bisected pits, represent significant movement of the tooth across the bone surface, and there is no indication of systematic biting, making crocodylian a poor match to the regular marks on TMP 2018.012.0123. Finally, the tooth marks left by modern large squamates are dominated by thin arcing scours, with rare pits and no crushing observed (D'Amore \& Blumenschine 2009). None of these features are consistent with the marks left on TMP 2018.012.0123.

Within Dinosauria, several clades of carnivorous (and potentially omnivorous) theropods represent potential tracemakers, including Tyrannosauridae, Dromaeosauridae, and Troodontidae. Of these potential tracemakers, Tyrannosauridae has the most comparative material for bite traces both in terms of described material and absolute number of marks. Tooth marks thought to have been delivered by tyrannosaurs are dominated by v-shaped furrows and scours (both (sub)parallel and isolated), as well as distinct puncture-and-drag marks, punctures, and fine parallel striae resulting from denticle scrapes (Jacobsen 1995; Erickson \& Olson 1996; Chin et al. 1997; Jacobsen 1998; Fowler \& Sullivan 2006; Hone \& Watabe 2010; Bell et al. 2012; Rivera-Sylva et al. 2012; Robinson et al. 2016). 
254

255

256

257

258

259

260

261

262

263

264

265

266

267

268

269

270

271

272

273

274

275

276

277

278

279

280

281

282

283

284

285

286

287

288

289

290

291

292

293

Dromaeosaurid tooth marks reported include those of Saurornitholestes, on the tibia a large azdarchid pterosaur (Currie \& Jacobsen 1995), those of a velociraptorine on Protoceratops bones, (Hone et al. 2010), and those thought to pertain to Deinonychus antirrhopus on the skeleton of Tenontosaurus (Gignac et al. 2010). In the former two cases the marks are shallow grooves or scours, while the latter case these are deeper V-shaped furrows. In addition to the scours and furrows, deeper, semi-circular 'bite and drag' marks have also been observed in velociraptorine (Hone et al. 2010), while deep punctures are described for Deinonychus (Gignac et al. 2010).

Fewer tooth marks attributable to Troodontidae are known, but Jacobsen and Bromley (2009) describe an example of the trace Linichnus serratus which they attribute to Troodon sp. Given their close relationship and general similarity to dromaeosaurs, they might, however, have left similar traces if they bit into bones.

Given the lack of evidence of denticle spacing present on bite marks, and that both Tyrannosauridae and Dromaeosauridae were capable of delivering bites resulting in deep furrows and pits to the bone surface, the relative size and shape of the tooth marks, and the spacing between these marks may help do determine which is a more likely tracemaker. As noted by Hone and Chure (2018), drawing direct correlation between spacing of (presumed) serial tooth marks and tooth spacing in potential trace makers may be problematic. Factors such as curved bone surfaces, bite angle, and missing or misaligned teeth may add additional variation to the resultant tooth mark spacing and may make elimination of potential trace makers more challenging (Hone \& Chure 2018). However, when a relatively consistent pattern of spacing between aligned tooth marks is observed, a most parsimonious first assumption is that this spacing is at least coarsely comparable to the spacing of teeth in the trace-making individual (Jacobsen 2003).

Comparisons between the spacing between the tooth marks on the ungual (Table 2), and the inter-tooth spacing of potential theropod trace-makers (Table 3) is shown in Fig. 3. The teeth (or alveoli) of the exemplar dentaries of the troodonid Stenonychosaurus inequalis average 2.7 or $3.4 \mathrm{~mm}$ in inter-tooth spacing (Table 3 ), significantly more closely spaced that the tooth marks in TMP 2018.012.0123 (Table 4, Fig. 4C, D).

For the two dromaeosaurid taxa, both Saurornitholestes langstoni and Dromaeosaurus albertensis are known from specimens that overlap the size range of the tooth marks on TMP 2018.012.0123. The Saurornitholestes dentary TMP 1988.121.0039 (mean inter-tooth spacing = $5.2 \mathrm{~mm}$ ) is not statistically different from the within-column tooth mark spacing (Table 4, Fig. 4E), while a larger specimen, TMP 1991.036.0112, (mean inter-tooth spacing $=7.6 \mathrm{~mm}$ ) is not statistically different from the within-row tooth mark spacing (Table 4, Fig. 3F). Similarly, the best specimen of Dromaeosaurus, AMNH 5356 (cast, TMP 1984.008.0001) shows inter-tooth spacing (mean $=7.7 \mathrm{~mm}$ ) that is not statistically different from the within-row tooth mark spacing (Table 4, Fig. 4G).

Relative to both Troodontidae and Dromaeosauridae, Tyrannosauridae is much better sampled from the Belly River Group, with a nearly complete ontogenetic series of jaws, missing 
294 only the smallest size classes. Given the small size of the tooth marks, and their close spacing 295 only small, immature, individuals could represent potential trace makers for tyrannosauridae. 296 The two smallest tyrannosaurid jaws from the Dinosaur Park Formation, the dentaries TMP 2971990.081 .0026 (mean spacing $=10.8)$ and TMP 1994.012.0155 (mean spacing $=12.0 \mathrm{~mm})$, both 298 show tooth spacing that is significantly greater than the spacing observed in TMP 2018.012.0123 299 (Table 4, Fig. 4H, I). While both these specimens are young juveniles (tooth row length of $3002018.012 .0123=165 \mathrm{~mm}$ ) they do not represent the youngest/smallest extreme of tyrannosaurid 301 ontogeny. It is possible that a younger/smaller tyrannosaur may have made the marks on TMP 302 2018.012.0123, but this would have to be a very immature individual smaller than that of any 303 jaw currently know from the Belly River and Edmonton groups - with a tooth row length $<165$ $304 \mathrm{~mm}$.

Given these data, it is not possible to confidently determine the taxonomy (or ontogeny) of the trace maker, but it can likely be narrowed down to either and adult-sized dromaeosaurid, or a very young tyrannosaurid. Regardless, these tooth marks suggest a potentially novel bone utilization, and may expand the evidence for bone utilization in Tyrannosauridae and/or Dromaeosauridae.

\section{Behavioral hypotheses}

Several possible behavior explanations may be put forward to explain the occurrence of such distinct tooth marks on the ungual.

Incidental contact while feeding - Regardless of whether the ungual was articulated with, or isolated from, the body, it would have had little meat in close association as represent a 'low economy' element (sensu Drumheller et al. 2020). While hadrosaur footprints indicated fleshy pads under the pedal phalanges (Langston Jr 1960; Currie et al. 1991), these would not have extended to the ungual, which would have largely been covered in a ketatinous hoof. While a keratinous hoof on the ungual would have had a very high protein content, keratin is resistant to vertebrate digestion, and was likely not a high value food item (Bragulla \& Homberger 2009). Indeed, there are few bones in a hadrosaur skeleton that would be either less desirable for consumption, or further from areas of high consumption priority. Actualistic taphonomic studies of carcass utilization by modern mammalian carnivores consistency recover the phalanges and unguals as being bones with some of the lowest frequency of modification (Dominguez-Rodrigo 1999; Rodríguez-Hidalgo et al. 2013; Arilla et al. 2014; Rodríguez-Hidalgo et al. 2015; Arilla et al. 2019) and these elements rank low in the carcass consumption sequence, and are largely used for their marrow (Blumenschine 1986; Marean et al. 1992). Additionally, the tooth marks on the bone surface of TMP 2018.012.0123 are not consistent with glancing contact between tooth and bone, but appear to be as a result of directly biting the bone surface. These tooth marks are not consistent with incidental marks during feeding, which appears to be the case for the majority of theropod tooth marks (Hone \& Rauhut 2010).

Predation/Grasping - It is possible that the bites were delivered to the prey animal while it was still alive, and are the result of active predation. In this hypothesis, the predator may have 
334 latched onto the hind foot of the hadrosaur with its jaws in an effort to it slow down and,

335

336

337

338

339

340

341

342

343

344

345

346

347

348

349

350

351

352

353

354

355

356

357

358

359

360

361

362

363

364

365

366

367

368

369

370

371

372

presumably with the combined effort of multiple individuals, bring down the prey. Multiple bites, and repositioning of the tooth row between bites, may be indicative of the struggle between prey-and-predator.

There are several problems with this hypothesis. Firstly, the differential between potential predator and prey size is extreme. Mass estimates for adult-sized potential tracemakers range from $16 \mathrm{~kg}$ and $18 \mathrm{~kg}$ for Dromaeosaurus albertensis and Saurornitholestes langstoni, to $57 \mathrm{~kg}$ for Troodon inequalis (Campione et al. 2014; Benson et al. 2018). Mass estimates for an immature tyrannosaur are more challenging. Given scaling of the skull length to body mass (Therrien \& Henderson 2007) in Theropoda, and femur to skull length in Tyrannosauridae (Currie 2003), and mass and femur length (Christiansen \& Fariña 2004), the lower jaw of TMP 1994.012 .0155 ( $29 \mathrm{~cm}$ long) would suggest a tyrannosaur tracemaker was no more than $32 \mathrm{~kg}$ (Therrien \& Henderson 2007) or $44 \mathrm{~kg}$ (Christiansen \& Fariña 2004). It should be noted that these estimation methods are not designed for immature individuals, are likely underestimates, and should be regarded as coarse at best. In comparison, adult-sized hadrosaurid taxa from Dinosaur Park Formation have mass estimates ranging from $>3,000$ to $>5,000 \mathrm{~kg}$ (Campione \& Evans 2012; Benson et al. 2018). This puts the mass of the hadrosaur at two orders of magnitude greater than the putative theropod tracemakers. This size differential is much greater than that seen between predator and prey in analogous systems (Hone \& Rauhut 2010). Given this size differential, it is difficult to believe that a theropod grabbing the rear ungual of a hadrosaur could not easily be kicked off. Further, if the multiple marks are interpreted as the result of a moving/struggling prey animal, one would expect there to be slippage and rotation of the marks, and the spacing and alignment of successive to be more irregular. Rather, the multiple bites are parallel and equidistant.

Play - Tyrannosaur tooth marks to isolated bones have been interpreted as evidence for play (Rothschild 2015). This hypothesis has been reviewed (Snively \& Samman 2015), and it has been pointed out that it makes few testable predictions, and is difficult to falsify. Object based play behavior is within the behavioral extant phylogenetic bracket for Dinosauria (Snively \& Samman 2015), so this behavior in a theropod dinosaur may not be unexpected. Given its difficulty to test, however, this hypothesis is not addressed in detail here, though we suggest that the repeated nature of the bites at a single location on the ungual do not easily align with the idea of play.

Late-stage carcass consumption - Perhaps the most likely hypothesis is that the tooth marks are result of late-stage carcass consumption (Hone \& Watabe 2010) (Fig. 5). Repeated, high powered bites delivered near the articular face of the ungual may have served to either sever or disarticulate the bone from the rest of the foot, or to break open the bone as part of a bone consumption strategy. The multiple parallel marks may be consistent with repositioning of the bite to produce better leverage as the tracemaker attempted to pull apart the skeleton. The hypothesis of late-stage carcass consumption is consistent with interpretations of other densely

Peer) reviewing PDF | (2021:02:57752:1:1:NEW 21 Apr 2021) 
373 tooth marked specimens attributable to tyrannosaurs (Erickson \& Olson 1996; Fowler \& Sullivan 374 2006; Hone \& Watabe 2010).

375 This specimen, however, differs from these other reports in several major ways. First, the 376 ungual is likely to have little to no flesh in association, especially compared to a ceratopsian 377 pelvis (Erickson \& Olson 1996; Fowler \& Sullivan 2006) or hadrosaur humerus (Hone \& 378 Watabe 2010). As such, this may represent an even more extreme example of late-stage carcass

379

380

381

382

383

384

385

386

387

388

389

390

391

392

393

394

395

396

397

398

399

400

401

402

403

404

405

406

407

408

409

410

411

412 consumption than these previous reports. Second, although these other specimens show a high number of tooth marks, and are consistent with multiple bites to a single bone, these bites (with the possible exception of the deltopectoral crest of the humerus (Hone \& Watabe 2010)) are not delivered to the same areas repeatedly. The marks to TMP 2018.012.0123 are restricted to a small area that was bitten up to six times. Third, previous records of bones with a high density of tyrannosaurid bite-marks are attributable Tyrannosaurinae; i.e. Daspletosaurus (Fowler \& Sullivan 2006), Tarbosaurus (Hone \& Watabe 2010), Tyrannosaurus (Erickson \& Olson 1996). The tooth mark described here, may be attributable to either Albertosaurinae (i.e., Gorgosaurus) or Tyrannosaurinae (i.e., Daspletosaurus) or to Dromaeosauridae, potentially broadening this behavior phylogenetically within Theropoda. Finally, these other reports document feeding behaviour in adult-size tyrannosaurs. If the bite marks described herein are from a tyrannosaur, they are from a very small, young individual, an individual at, or below, the size of the smallest known articulated skulls. It is unclear, however, if the purpose of the repeated, localized bites was to dismember the ungual from the rest of an articulated foot to expose articular cartilage or tendon, to break open the bone to exposed the marrow, or for some other purpose.

\section{Bone utilization by theropod dinosaurs}

A recent study on theropod tooth mark frequency on bones from the Upper Jurassic Mygatt-Moore Quarry (Drumheller et al. 2020), showed a high mark frequency on similar 'low economy' bones (e.g., equivalent to the ungual), a frequency that was higher than 'high economy' bones. This suggested high rates of scavenging and potentially representative of a highly-stressed environment. While this is consistent with the marks seen in TMP 2018.012.0123 this may be an exception as the frequency of marks on other unguals and 'low economy' bones appears to be quite low, and in this regard the pattern of bite marks in the Dinosaur Park Formation is largely distinct from the Mygatt-Moore Quarry (Jacobsen 1998).

We suggest that the general lower levels of bone exploitation by non-avian theropods may be linked to their difficulty of accessing the marrow cavity. Mammals may have proportionally larger marrow cavities than do dinosaurs (particularly ornithischians) for a given bone diameter, but in any case, large dinosaurs will have absolutely thicker bone walls compared to mammals (e.g. sauropods and large ornithischians have absolutely larger femora than any living terrestrial mammals aside from, perhaps, elephants). Furthermore, large mammalian carnivores typically have more robust teeth for their size than do non-tyrannosaurid theropods so overall would have a greater ability to process bone to obtain the marrow than most theropods. Together these factors may explain the distinction in bone utilization between the two clades. 
413 The bones of dinosaurian juveniles or small taxa could still be broken and /or consumed and thus

414 destroyed, but the lack of bite traces on large dinosaurian elements may at least in part reflect an 415 inability to break into them.

416 It should be noted that some living birds (extant avian theropods), while not engaging in 417 gnawing behaviour on bones, do make extensive use of bone as a dietary source. The most 418 extreme example of this is the bearded vulture (Gypaetus barbatus), for which bones make up 419 the majority of the diet, and generally derive from much larger animals (Brown \& Plug 1990; 420 Margalida et al. 2009). As such, bone utilization strategies across Theropoda be more complex 421 then previously realized.

422

423

\section{Conclusions}

424

425

426

427

428

429

430

431

432

433

434

435

436

437

438

439

440

441

442

443

444

445

446

447

448

449

450

451

452

A hadrosaurid pedal ungual bears a distinct pattern of tooth marks suggesting multiple, repeated, bites delivered to a restricted area of the element, and powerful enough the penetrate much of the bone cortex. The morphology, size and spacing of the tooth marks suggest the tracemaker was a small-to-medium sized theropod dinosaur, likely a dromaeosaurid or young tyrannosaur. This behavior is most consistent with late-stage carcass consumption of an element that had limited association with the soft tissue considered to be the primary food source. Theropod bite marks on other hadrosaur unguals are known, but appear to occur at a very low frequency.

The traces left on these unguals, particularly TMP 2018.012.0123, are largely consistent with those left by gnawing behaviour. The mechanism of the bone processing behaviour is at least superficially similar to gnawing in mammals, and may represent "gnawing-like" behavior. Indeed, if similar marks were left on a bone from a mammalian carnivore, "gnawing" would likely be considered an appropriate term. This specimen expands our understanding of prey bone utilization behavior in non-avian theropods dinosaurs, representing the strongest case for "gnawing-like" behavior in this clade. The occurrence of this prey bone utilization is also expanded, either phylogenetically into Dromaeosauridae, or ontogenetically into young tyrannosaurids.

\section{Acknowledgements}

TMP 2018.012.0123 was found by E. L. Clare, as part of the Queen Mary University of London - Royal Tyrrell Museum of Palaeontology field school in 2018. The authors thank Alberta Parks staff, specifically J. Blacklaws, for logistical support of this field school. UALVP 55092 was collected by C. Coy, and TMP 1979.008.0769 and TMP 1980.016.1215 were collected by J. Bahr and P. Currie respectively. Access to collections and specimen assistance was facilitated by T. Courtenay, H. Feeney, R. Russell, B. Sanchez and B. Strilisky (RTMP), and H. Gibbins, C. Coy and P. Currie (UALVP). D. Brinkman provided materials and assistance for ammonium chloride powder coating. I. Macdonald brought UALVP 55092 specimen to our attention, and provided the photograph. D. Evans, N. Gardner and F. Varriale provided useful discussion. Josh

PeerJ reviewing PDF | (2021:02:57752:1:1:NEW 21 Apr 2021) 
453 Doyon created the artwork in Figure 5. Phil Bell, James Farlow, Domenic D'Amore (reviewers)

454 and Fabian Knoll (academic editor) provided feedback which improved the paper.

455

456

457

458

459

460

461

462

463

464

465

466

467

468

469

470

471

472

473

474

475

476

477

478

479

480

481

482

483

484

485

486

487

488

489

490

491

492

493

494

495

496

497

\section{References}

Arilla M, Rosell J, and Blasco R. 2019. Contributing to characterise wild predator behaviour: consumption pattern, spatial distribution and bone damage on ungulate carcasses consumed by red fox (Vulpes vulpes). Archaeological and Anthropological Sciences 11:2271-2291.

Arilla M, Rosell J, Blasco R, Dominguez-Rodrigo M, and Pickering TR. 2014. The "bear" essentials: Actualistic research on Ursus arctos arctos in the Spanish Pyrenees and its implications for paleontology and archaeology. PLoS ONE 9:e102457.

Bell PR, Currie PJ, and Lee Y-N. 2012. Tyrannosaur feeding traces on Deinocheirus (Theropoda:? Ornithomimosauria) remains from the Nemegt Formation (Late Cretaceous), Mongolia. Cretaceous Research 37:186-190.

Benson RB, Hunt G, Carrano MT, and Campione N. 2018. Cope's rule and the adaptive landscape of dinosaur body size evolution. Palaeontology 61:13-48.

Blumenschine RJ. 1986. Carcass consumption sequences and the archaeological distinction of scavenging and hunting. Journal of Human Evolution 15:639-659.

Botfalvai G, Prondvai E, and Ösi A. 2014. Inferred bite marks on a Late Cretaceous (Santonian) bothremydid turtle and a hylaeochampsid crocodilian from Hungary. Cretaceous Research 50:304-317.

Boyd CA, Drumheller SK, and Gates TA. 2013. Crocodyliform feeding traces on juvenile ornithischian dinosaurs from the Upper Cretaceous (Campanian) Kaiparowits Formation, Utah. PLoS ONE 8:e57605.

Bragulla HH, and Homberger DG. 2009. Structure and functions of keratin proteins in simple, stratified, keratinized and cornified epithelia. Journal of Anatomy 214:516-559.

Bramble K, Currie PJ, Tanke DH, and Torices A. 2017. Reuniting the "head hunted" Corythosaurus excavatus (Dinosauria: Hadrosauridae) holotype skull with its dentary and postcranium. Cretaceous Research 76:7-18.

Brown C, and Plug I. 1990. Food choice and diet of the Bearded Vulture Gypaetus barbatus in southern Africa. African Zoology 25:169-177.

Cambridge Dictionary T. 2016. The Cambridge English Dictionary. [online] Available at: $<$ http://dictionary.cambridge.org/dictionary/english/occupation $>$ (accessed January 11, 20212021 ).

Campione NE, and Evans DC. 2012. A universal scaling relationship between body mass and proximal limb bone dimensions in quadrupedal terrestrial tetrapods. BMC biology 10:60.

Campione NE, Evans DC, Brown CM, and Carrano M. 2014. Body mass estimation in non-avian bipeds using a theoretical conversion to quadruped stylopodial proportions. Methods in Ecology and Evolution 5:913-923.

Chin K, Eberth DA, Schweitzer MH, Rando TA, Sloboda WJ, and Horner JR. 2003. Remarkable preservation of undigested muscle tissue within a Late Cretaceous tyrannosaurid coprolite from Alberta, Canada. Palaios 18:286-294.

Chin K, Farlow J, and Brett-Surman M. 1997. What did dinosaurs eat? Coprolites and other direct evidence of dinosaur diets. In: Farlow JA, and Brett-Surman MK, eds. The Complete Dinosaur. Bloomington: Indiana University Press, 371-382.

PeerJ reviewing PDF | (2021:02:57752:1:1:NEW 21 Apr 2021) 
498

499

500

501

502

503

504

505

506

507

508

509

510

511

512

513

514

515

516

517

518

519

520

521

522

523

524

525

526

527

528

529

530

531

532

533

534

535

536

537

538

539

540

541

542
Chin K, Tokaryk TT, Erickson GM, and Calk LC. 1998. A king-sized theropod coprolite. Nature 393:680-682.

Christiansen P, and Fariña RA. 2004. Mass prediction in theropod dinosaurs. Historical Biology 16:85-92.

Chure DJ, Fiorillo AR, and Jacobsen A. 1998. Prey bone utilization by predatory dinosaurs in the Late Jurassic of North America, with comments on prey bone use by dinosaurs throughout the Mesozoic. Gaia 15:227-232.

Currie PJ. 1987. Bird-like characteristics of the jaws and teeth of troodontid theropods (Dinosauria, Saurischia). Journal of Vertebrate Paleontology 7:72-81.

Currie PJ. 1995. New information on the anatomy and relationships of Dromaeosaurus albertensis (Dinosauria: Theropoda). Journal of Vertebrate Paleontology 15:576-591.

Currie PJ. 2003. Allometric growth in tyrannosaurids (Dinosauria: Theropoda) from the Upper Cretaceous of North America and Asia. Canadian Journal of Earth Sciences 40:651-665.

Currie PJ, and Jacobsen AR. 1995. An azhdarchid pterosaur eaten by a velociraptorine theropod. Canadian Journal of Earth Sciences 32:922-925.

Currie PJ, Nadon GC, and Lockley MG. 1991. Dinosaur footprints with skin impressions from the Cretaceous of Alberta and Colorado. Canadian Journal of Earth Sciences 28:102115.

D'Amore DC, and Blumenschine RJ. 2009. Komodo monitor (Varanus komodoensis) feeding behavior and dental function reflected through tooth marks on bone surfaces, and the application to ziphodont paleobiology. Paleobiology 35:525-552.

Dalman SG, and Lucas SG. 2021. New evidence for cannibalism in tyrannosaurid dinosaurs from the Upper Cretaceous (Campanian/Maastrichtian) San Juan Basin of New Mexico. New Mexico Museum of Natural History and Science Bulletin 82:39-56.

Domínguez-Rodrigo M. 1999. Flesh availability and bone modifications in carcasses consumed by lions: palaeoecological relevance in hominid foraging patterns. Palaeogeography, Palaeoclimatology, Palaeoecology 149:373-388.

Drumheller SK, and Brochu CA. 2014. A diagnosis of Alligator mississippiensis bite marks with comparisons to existing crocodylian datasets. Ichnos 21:131-146.

Drumheller SK, McHugh J, B., Kane M, Riedel A, and D’Amore D. 2020. High frequencies of theropod bite marks provide evidence for feeding, scavenging, and possible cannibalism in a stressed Late Jurassic ecosystem. PLoS ONE 15. https://doi.org/10.1371/journal.pone.0233115

Eberth DA, and Evans DC. 2011. International Hadrosaur Symposium Guide Book. Drumheller: Royal Tyrrell Museum of Palaeontology.

Erickson GM, and Olson KH. 1996. Bite marks attributable to Tyrannosaurus rex: preliminary description and implications. Journal of Vertebrate Paleontology 16:175-178.

Fiorillo AR. 1991. Prey bone utilization by predatory dinosaurs. Palaeogeography, Palaeoclimatology, Palaeoecology 88:157-166.

Fowler DW, and Sullivan RM. 2006. A ceratopsid pelvis with toothmarks from the Upper Cretaceous Kirtland Formation, New Mexico: Evidence of Late Campanian tyrannosaurid feeding behavior. New Mexico Museum of Natural History and Science Bulletin 35:127-130.

Gignac PM, and Erickson GM. 2017. The biomechanics behind extreme osteophagy in Tyrannosaurus rex. Scientific reports 7:1-10.

Peer] reviewing PDF | (2021:02:57752:1:1:NEW 21 Apr 2021) 
543 Gignac PM, Makovicky PJ, Erickson GM, and Walsh RP. 2010. A description of Deinonychus

544

545

546

547

548

549

550

551

552

553

554

555

556

557

558

559

560

561

562

563

564

565

566

567

568

569

570

571

572

573

574

575

576

577

578

579

580

581

582

583

584

585

586 antirrhopus bite marks and estimates of bite force using tooth indentation simulations. Journal of Vertebrate Paleontology 30:1169-1177.

Haynes G. 1980. Evidence of carnivore gnawing on Pleistocene and Recent mammalian bones. Paleobiology 6:341-351.

Haynes G. 1983. A guide for differentiating mammalian carnivore taxa responsible for gnaw damage to herbivore limb bones. Paleobiology 9:164-172.

Hone D, Choiniere J, Sullivan C, Xu X, Pittman M, and Tan Q. 2010. New evidence for a trophic relationship between the dinosaurs Velociraptor and Protoceratops. Palaeogeography, Palaeoclimatology, Palaeoecology 291:488-492.

Hone DW, and Chure DJ. 2018. Difficulties in assigning trace makers from theropodan bite marks: an example from a young diplodocoid sauropod. Lethaia 51:456-466.

Hone DW, and Rauhut OW. 2010. Feeding behaviour and bone utilization by theropod dinosaurs. Lethaia 43:232-244.

Hone DW, Tanke DH, and Brown CM. 2018. Bite marks on the frill of a juvenile Centrosaurus from the Late Cretaceous Dinosaur Provincial Park Formation, Alberta, Canada. PeerJ 6:e5748.

Hone DW, and Watabe M. 2010. New information on scavenging and selective feeding behaviour of tyrannosaurids. Acta Palaeontologica Polonica 55:627-634.

Hurum JrH, and Currie PJ. 2000. The crushing bite of tyrannosaurids. Journal of Vertebrate Paleontology 20:619-621.

Jacobsen A. 1995. Predatory behaviour of carnivorous dinosaurs: ecological interpretations based on tooth marked dinosaur bones and wear patterns of theropod teeth M.Sc. University of Copenhagen.

Jacobsen AR. 1998. Feeding behaviour of carnivorous dinosaurs as determined by tooth marks on dinosaur bones. Historical Biology 13:17-26.

Jacobsen AR. 2003. Predatory Behaviour of Carnivorous Dinosaurs: Ecological Interpretations Based on Tooth Marked Dinosaur Bones and Wear Patterns of Theropod Teeth: Judith River Group (Upper Cretaceous, Campanian), Alberta, Canada: Steno Museum, University of Aarhus.

Jacobsen AR, and Bromley RG. 2009. New ichnotaxa based on tooth impressions on dinosaur and whale bones. Geological Quarterly 53:373-382.

Kruuk H. 1972. The spotted hyena: a study of predation and social behavior.

Langston Jr W. 1960. A hadrosaurian ichnite. Natural History Papers, National Museum of Canada 4:1-9.

Longrich NR, Horner JR, Erickson GM, and Currie PJ. 2010. Cannibalism in Tyrannosaurus rex. PLOS ONE 5:e13419.

Longrich NR, and Ryan MJ. 2010. Mammalian tooth marks on the bones of dinosaurs and other Late Cretaceous vertebrates. Palaeontology 53:703-709.

Marean CW, Spencer LM, Blumenschine RJ, and Capaldo SD. 1992. Captive hyaena bone choice and destruction, the schlepp effect and Olduvai archaeofaunas. Journal of archaeological science 19:101-121.

Margalida A, Bertran J, and Heredia R. 2009. Diet and food preferences of the endangered Bearded Vulture Gypaetus barbatus: a basis for their conservation. Ibis 151:235-243. 
587

588

589

590

591

592

593

594

595

596

597

598

599

600

601

602

603

604

605

606

607

608

609

610

611

612

613

614

615

616

617

618

619

620

621

622

623

624

625

626

627

628

629

630

631

632

Njau JK, and Blumenschine RJ. 2006. A diagnosis of crocodile feeding traces on larger mammal bone, with fossil examples from the Plio-Pleistocene Olduvai Basin, Tanzania. Journal of Human Evolution 50:142-162.

Noto CR, Main DJ, and Drumheller SK. 2012. Feeding traces and paleobiology of a Cretaceous (Cenomanian) crocodyliform: example from the Woodbine Formation of Texas. Palaios 27:105-115.

Parks WA. 1920. The osteology of the trachodont dinosaur Kritosaurus incurvimanus. University of Toronto Studies, Geological Series 11:1-76.

Parsley RL, Lawson MH, and Pojeta Jr J. 2018. A Practical and Historical Perspective of the How and Why of Whitening Fossil Specimens and Casts as a Precurser to Their Photography. Fossil Imprint 74:237-244.

Prieto-Márquez A. 2014. A juvenile Edmontosaurus from the late Maastrichtian (Cretaceous) of North America: implications for ontogeny and phylogenetic inference in saurolophine dinosaurs. Cretaceous Research 50:282-303.

Rivera-Sylva HE, Hone DW, and Dodson P. 2012. Bite marks of a large theropod on an hadrosaur limb bone from Coahuila, Mexico. Boletín de la Sociedad Geológica Mexicana 64:155-159.

Robinson RF, Jasinski SE, and Sullican RM. 2016. Theropod bite marks on dinosaur bones: indications of a scavenger, predator or both?; and their taphonomic implications. New Mexico Museum of Nature and Science, Fossil Record 4 67:275.

Rodríguez-Hidalgo A, Lloveras L, Moreno-García M, Saladié P, Canals A, and Nadal J. 2013. Feeding behaviour and taphonomic characterization of non-ingested rabbit remains produced by the Iberian lynx (Lynx pardinus). Journal of archaeological science 40:3031-3045.

Rodríguez-Hidalgo A, Saladié P, Marín J, and Canals A. 2015. Expansion of the referential framework for the rabbit fossil accumulations generated by Iberian lynx. Palaeogeography, Palaeoclimatology, Palaeoecology 418:1-11.

Rothschild BM. 2015. Unexpected behavior in the Cretaceous: tooth-marked bones attributable to tyrannosaur play. Ethology Ecology \& Evolution 27:325-334.

Snively E, and Samman T. 2015. Unexpected behavior in the Cretaceous: tooth-marked bones attributable to tyrannosaur play. A comment by E. Snively \& T. Samman. Ethology Ecology \& Evolution 27:422-427.

Tanke DH, and Brett-Surman MK. 2001. Evidence of hatchling-and nestling-size hadrosaurs (Reptilia: Ornithischia) from Dinosaur Provincial Park (Dinosaur Park Formation: Campanian), Alberta. In: Tanke DH, and Carpenter K, eds. Mesozoic vertebrate life: Indiana University Press, 206-218.

Tanke DH, and Russell R. 2012. Headless wonder: Possible evidence of a head-hunted dinosaur skeleton in Dinosaur Provincial Park, Alberta. Alberta Palaeontological Society Annual Symposium. Mount Royal University, Calgary, Alberta. p 14-17.

Team RDC. 2009. R: A Language and Environment for Statistical Computing. Version 2.10.0 ed. Vienna, Austria: R Foundation for Statistical Computing.

Therrien F, and Henderson DM. 2007. My theropod is bigger than yours.... or not: estimating body size from skull length in theropods. Journal of Vertebrate Paleontology 27:108115.

Tseng ZJ. 2013. Testing adaptive hypotheses of convergence with functional landscapes: a case study of bone-cracking hypercarnivores. PLOS ONE 8:e65305.

Peer) reviewing PDF | (2021:02:57752:1:1:NEW 21 Apr 2021) 
633 Van Valkenburgh B. 1996. Feeding behavior in free-ranging, large African carnivores. Journal 634 of Mammalogy 77:240-254.

635

636

637

638

639

640

641

642

643

644

645

646

647

648

649

650

651

652

653

654

655

656

657

658

659

660

661

662

663

664

665

666

667

668

669

670

671

672

673

Van Valkenburgh B. 2007. Déjà vu: the evolution of feeding morphologies in the Carnivora. Integrative and Comparative Biology 47:147-163.

Zheng R, Farke AA, and Kim G-S. 2011. A photographic atlas of the pes from a hadrosaurine hadrosaurid dinosaur. PalArch's Journal of Vertebrate Palaeontology 8:01-12.

\section{Figure Captions:}

Figure 1: Ammonium chloride powder coated photographs of the hadrosaurid pedal ungual TMP 2018.012.0123 showing bite marks (ventral/plantar view). (A) View of entire specimen, with marks highlighted in blue (A'). (B) Close up of the bitten region, with marks highlighted in blue and numbered in Arabic numerals (B'). All scale bars $=1 \mathrm{~cm}$.

Figure 2: Position and orientation of bite marks on ungual and within hadrosaur pes. (A) Right articulated hadrosaurid pes in dorsal view, with in ungual of digit three highlighted (white) and the position of the tooth marks (ventral side) indicated in black - modified from (Prieto-Márquez 2014). (B) shaded line drawing of the ventral (plantar) view of the ungual TMP 2018.012.0123, showing the position of the bite marks (black). (C) Close up view of bite mark size, shape, and orientation, showing alignment of bites in rows (Roman numerals) and columns (lowercase letters) indicated by dotted lines (based on Fig. 1B). (D) Close up view of bite marks showing potential alignment of tooth row parallel with the long axes of the tooth marks. Hollow fills in C indicate potential bite marks missing from rows $/$ columns. All scale bars $=1 \mathrm{~cm}$.

Figure 3: Photographs (upper) and interpretive drawings (lower) of three isolated hadrosaurid pedal unguals with theropod toothmarks. (A) UALVP55092 in ventral (plantar) view, (B) TMP 1979.008.0769 in dorsal view, (C) TMP 1980.016.1215 in dorsal view. In lower drawings hatched areas indicate missing bone surface, dashed lines are approximate margins, and black indicates tooth marks. All specimens to same scale. Scale bar $=1 \mathrm{~cm}$.

Figure 4. Size comparison of spacing between subsequent tooth marks on TMP 2018.012.0123 (A, B, J), and exemplars of potential theropod trace making taxa (C-I, K-N). (A-I) Histograms showing distributions on spacing between tooth marks (A, B) and teeth/alveoli (C-1): (A, B) TMP2018.012.0123, for rows (A) and column (B); (C, D) Stenonychosaurus inequalis - TMP 1967.014.0039, and 1982.016.0138; (E, F) Saurornitholestes langstoni - TMP 1988.121.0039 and 1991.036.0112; (G) Dromaeosaurus albertensis - TMP 1984.008.0001 (cast of AMNH 5356), and H, I) juvenile Gorgosaurus libratus - TMP 1990.081.0026 and 1994.012.0155. J-N) Scaled line drawings illustrating the morphology and size of the tooth traces exemplar dentaries (J) ungual TMP 2018.012.0123 in ventral view, with tooth marks shown in black; (K) medial view of reconstructed Stenonychosaurus inequalis (Troodontidae) dentary based on CMN 8540, redrawn from (Currie 1987); (L) medial view of complete dentary of Saurornitholestes langstoni

PeerJ reviewing PDF | (2021:02:57752:1:1:NEW 21 Apr 2021) 
674 (Dromaeosauridae) - based on TMP 1988.121.0039; (M) lateral view of complete dentary of

675 Dromaeosaurus albertensis (Dromaeosauridae) - based on AMNH 5356, redrawn from (Currie 676 1995), (N) medial view of a dentary of a juvenile Gorgosaurus libratus (Tyrannosauridae) 677 based on TMP 1994.012.0155. Lines above dentaries indicates tooth size/alveolar spacing. 678 Significance values: $* \alpha=0.05,{ }^{*} \alpha=0.01, * * * \alpha=0.001, \mathrm{~ns}=$ not significant - See Table 4. 679 All specimens to same scale. Scale bar $=1 \mathrm{~cm}$.

680

681 Figure 5. Artistic reconstruction of one potential scenario causing the tooth marks on TMP 682 2018.012.0123: A juvenile tyrannosaurid bites down on a hadrosaur ungual as part of a late-stage 683 carcass consumption strategy.

684

685 Table 1: Linear measurements of the 13 tooth marks on TMP 2018.012.0123. See Fig. 1B for 686 mark numbers.

687

688 Table 2: Spacing between successive tooth marks by both row (i, ii, etc.) and column (a, b, etc.) 689 on TMP 2018.012.0123. See Fig. 2C for row and column designation.

690

691 Table 3: Spacing between successive tooth positions (or alveoli) in tooth rows across specimens 692 of several potential tracemakers.

693

694 Table 4: Results of Kolmogorov-Smirnov test (two sample), comparing the spacing between 695 successive tooth positions (or alveoli) in TMP 2018.012.0123 with specimens of several 696 potential tracemakers. Bold values are significantly different, $\alpha<0.05$.

697 


\section{Figure 1}

Ammonium chloride powder coated photographs of the hadrosaurid pedal ungual TMP 2018.012.0123 showing bite marks (ventral/plantar view).

(A) View of entire specimen, with marks highlighted in blue ( $\left.A^{\prime}\right)$. (B) Close up of the bitten region, with marks highlighted in blue and numbered in Arabic numerals $\left(B^{\prime}\right)$. All scale bars $=$ $1 \mathrm{~cm}$.

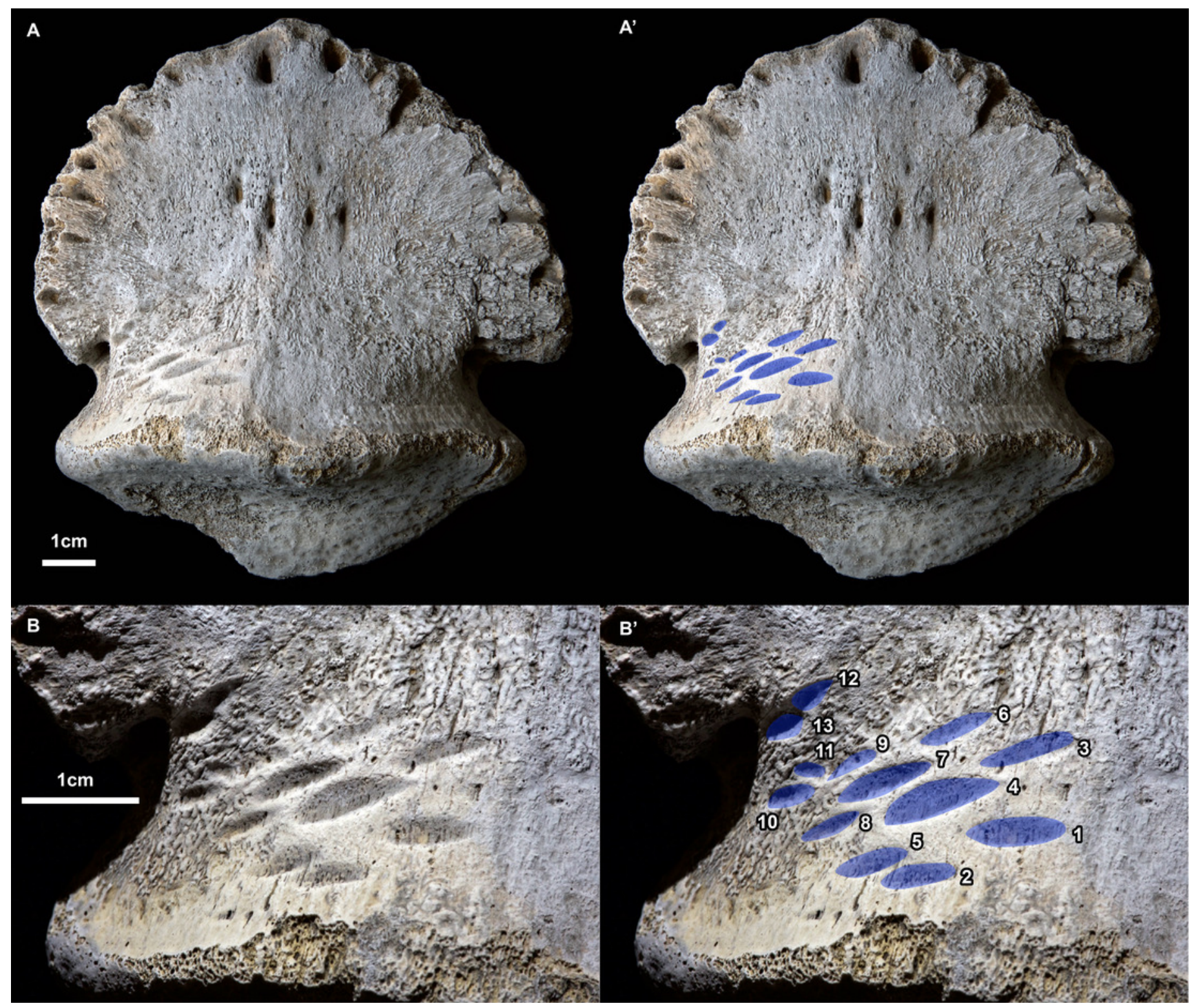




\section{Figure 2}

Position and orientation of bite marks on ungual and within hadrosaur pes.

(A) Right articulated hadrosaurid pes in dorsal view, with in ungual of digit three highlighted (white) and the position of the tooth marks (ventral side) indicated in black - modified from (Prieto-Márquez 2014) . (B) shaded line drawing of the ventral (plantar) view of the ungual TMP 2018.012.0123, showing the position of the bite marks (black). (C) Close up view of bite mark size, shape, and orientation, showing alignment of bites in rows (Roman numerals) and columns (lowercase letters) indicated by dotted lines (based on Fig. 1B). (D) Close up view of bite marks showing potential alignment of tooth row parallel with the long axes of the tooth marks. Hollow fills in $\mathrm{C}$ indicate potential bite marks missing from rows/columns. All scale bars $=1 \mathrm{~cm}$. 

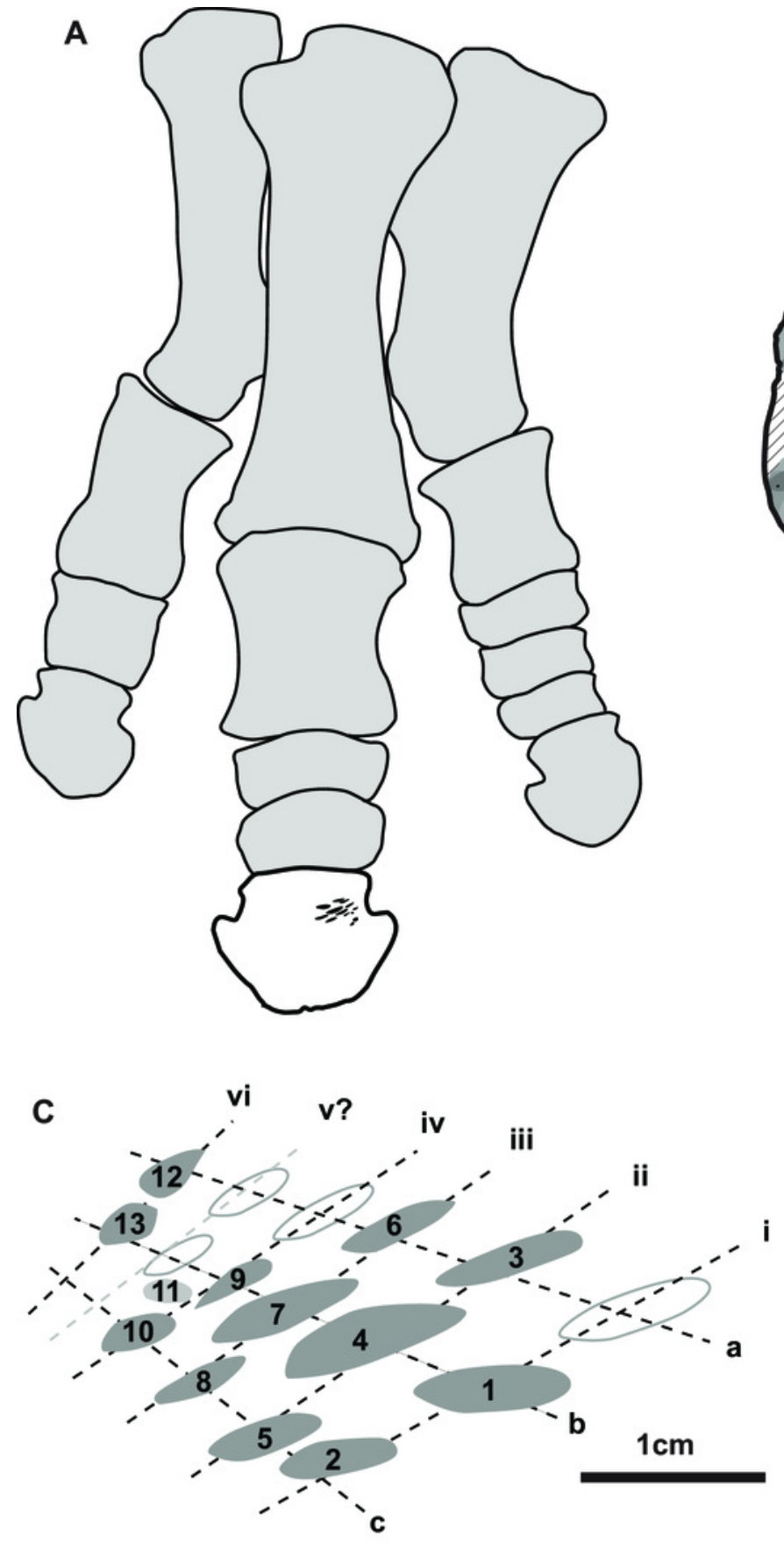

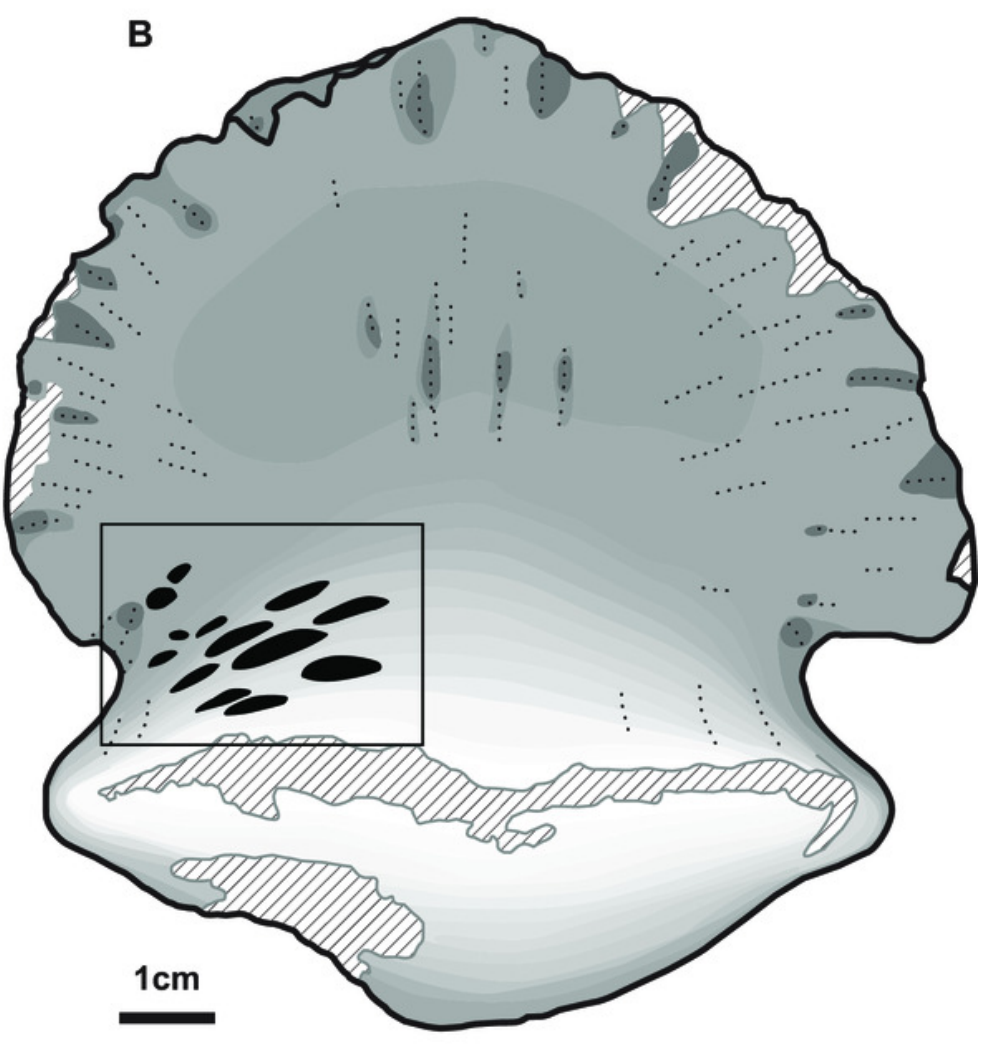

D

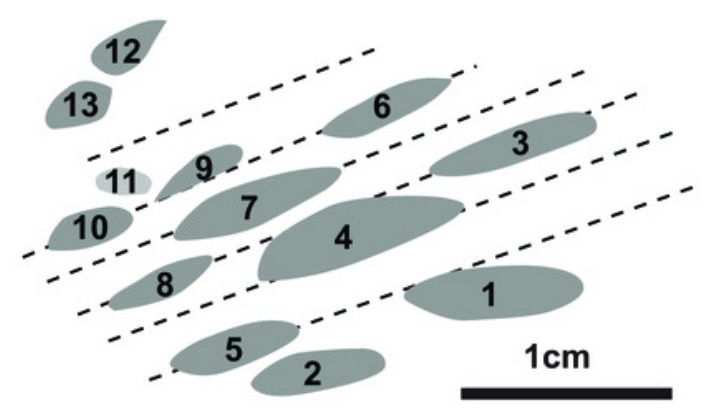




\section{Figure 3}

Photographs (upper) and interpretive drawings (lower) of three isolated hadrosaurid pedal unguals with theropod toothmarks.

(A) UALVP55092 in ventral (plantar) view, (B) TMP 1979.008.0769 in dorsal view, (C) TMP 1980.016.1215 in dorsal view. In lower drawings hatched areas indicate missing bone surface, dashed lines are approximate margins, and black indicates tooth marks. All specimens to same scale. Scale bar $=1 \mathrm{~cm}$. Photograph in Figure 3A coutesy of lan Macdonald.

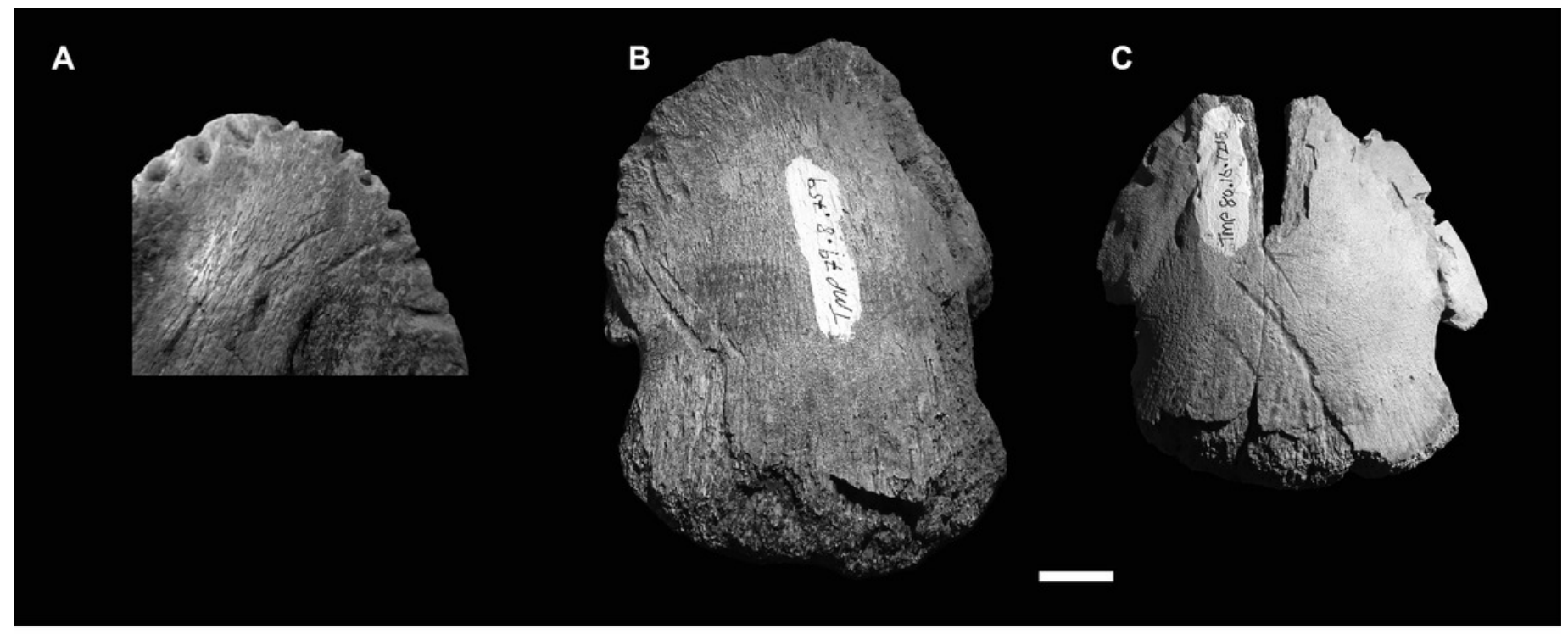

$\mathbf{A}^{\prime}$

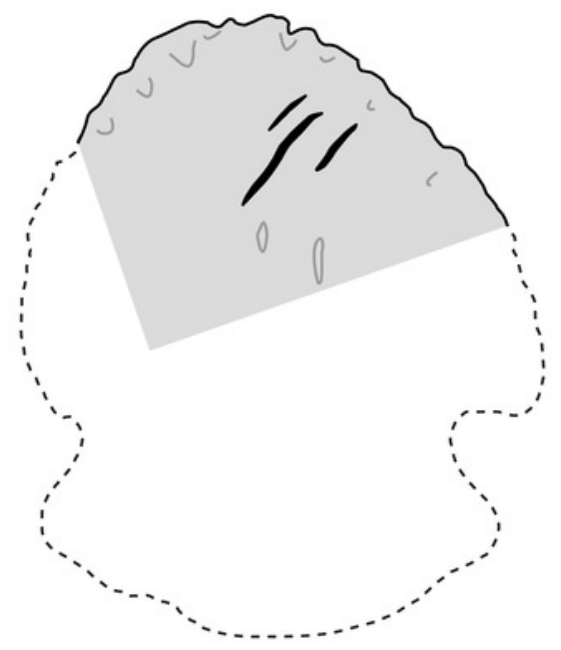

B'

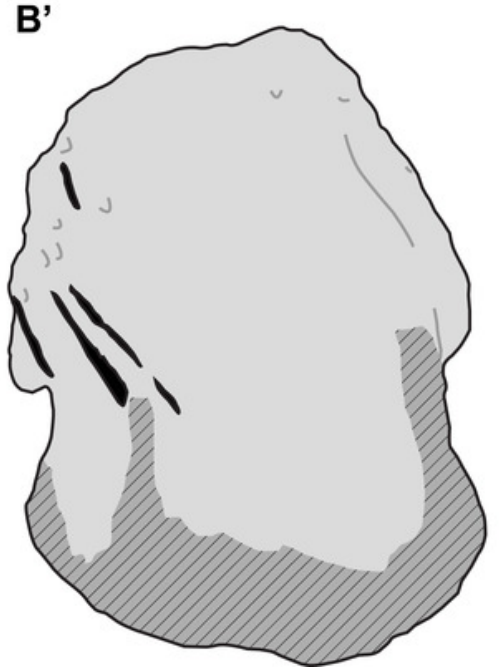

$C^{\prime}$

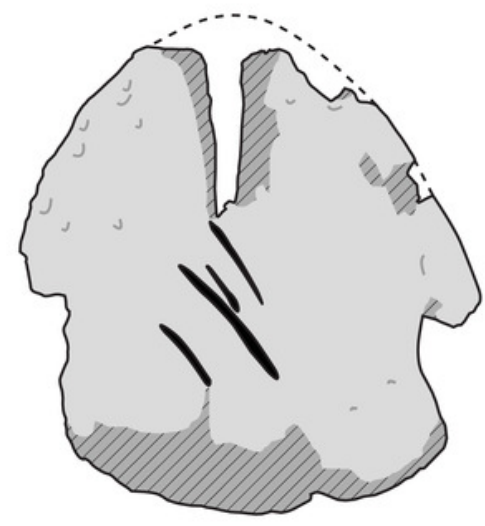




\section{Figure 4}

Size comparison of spacing between subsequent tooth marks on TMP 2018.012.0123 (A, $\mathrm{B}, \mathrm{J})$, and exemplars of potential theropod trace making taxa (C-I, K-N).

(A-I) Histograms showing distributions on spacing between tooth marks (A, B) and teeth/alveoli (C-1): (A, B) TMP2018.012.0123, for rows (A) and column (B); (C, D) Stenonychosaurus inequalis - TMP 1967.014.0039, and 1982.016.0138; (E, F) Saurornitholestes langstoni - TMP 1988.121.0039 and 1991.036.0112; (G) Dromaeosaurus albertensis - TMP 1984.008.0001 (cast of AMNH 5356), and H, I) juvenile Gorgosaurus libratus - TMP 1990.081.0026 and 1994.012.0155. J-N) Scaled line drawings illustrating the morphology and size of the tooth traces exemplar dentaries (J) ungual TMP 2018.012.0123 in ventral view, with tooth marks shown in black; $(K)$ medial view of reconstructed Stenonychosaurus inequalis (Troodontidae) dentary based on CMN 8540, redrawn from (Currie 1987) ; (L) medial view of complete dentary of Saurornitholestes langstoni (Dromaeosauridae) - based on TMP 1988.121.0039; (M) lateral view of complete dentary of Dromaeosaurus albertensis (Dromaeosauridae) - based on AMNH 5356, redrawn from (Currie 1995) , (N) medial view of a dentary of a juvenile Gorgosaurus libratus (Tyrannosauridae) based on TMP 1994.012.0155. Lines above dentaries indicates tooth size/alveolar spacing. Significance values: $* \alpha=0.05,{ }^{* *} \alpha=0.01,{ }^{* * *} \alpha=0.001, \mathrm{~ns}=$ not significant - See Table 4 . All specimens to same scale. Scale bar $=1 \mathrm{~cm}$. 


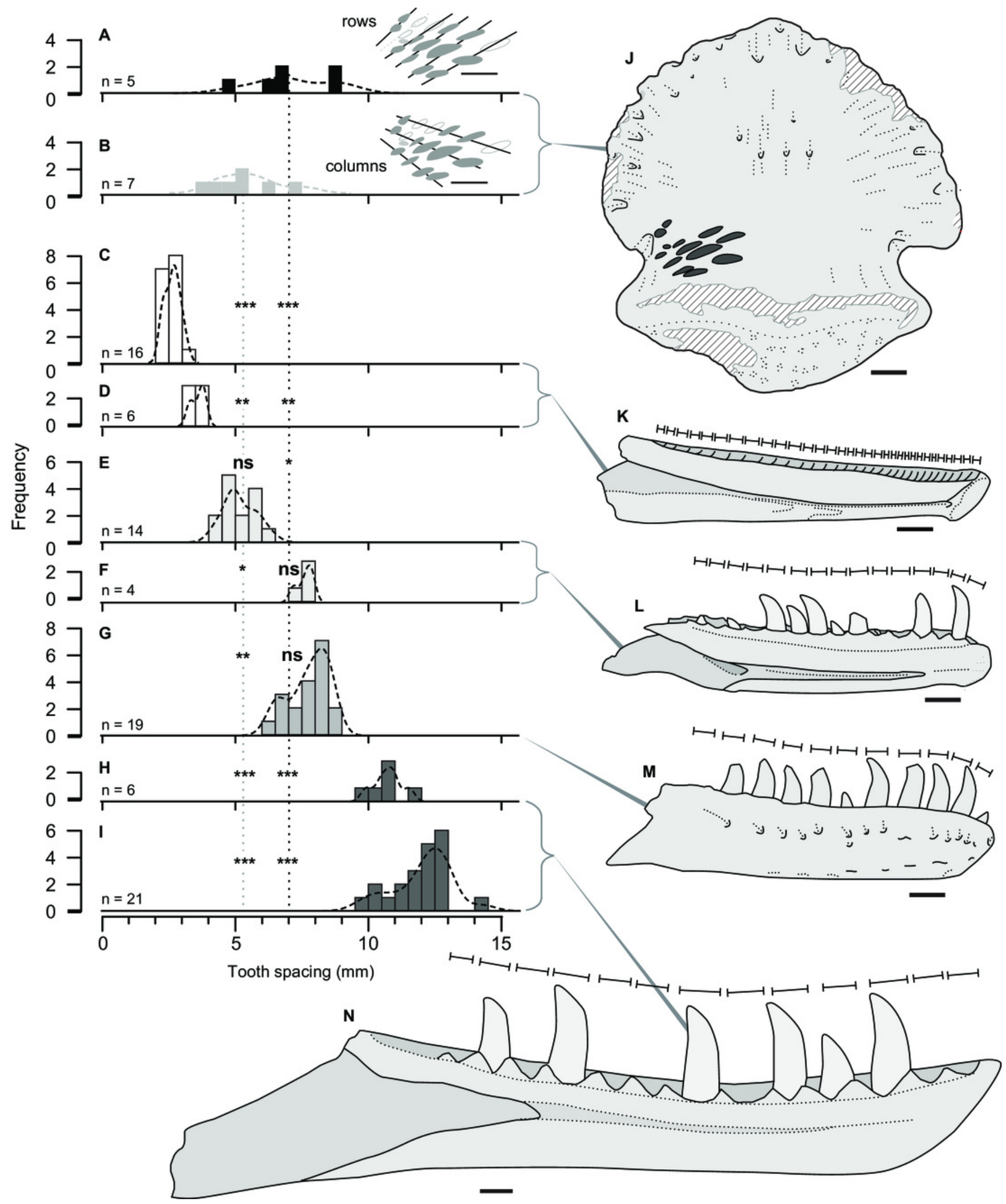


Figure 5

Artistic reconstruction of one potential scenario causing the tooth marks on TMP 2018.012.0123.

A juvenile tyrannosaurid bites down on a hadrosaur ungual as part of a late-stage carcass consumption strategy. Artwork courtesy of Joshua Doyon.

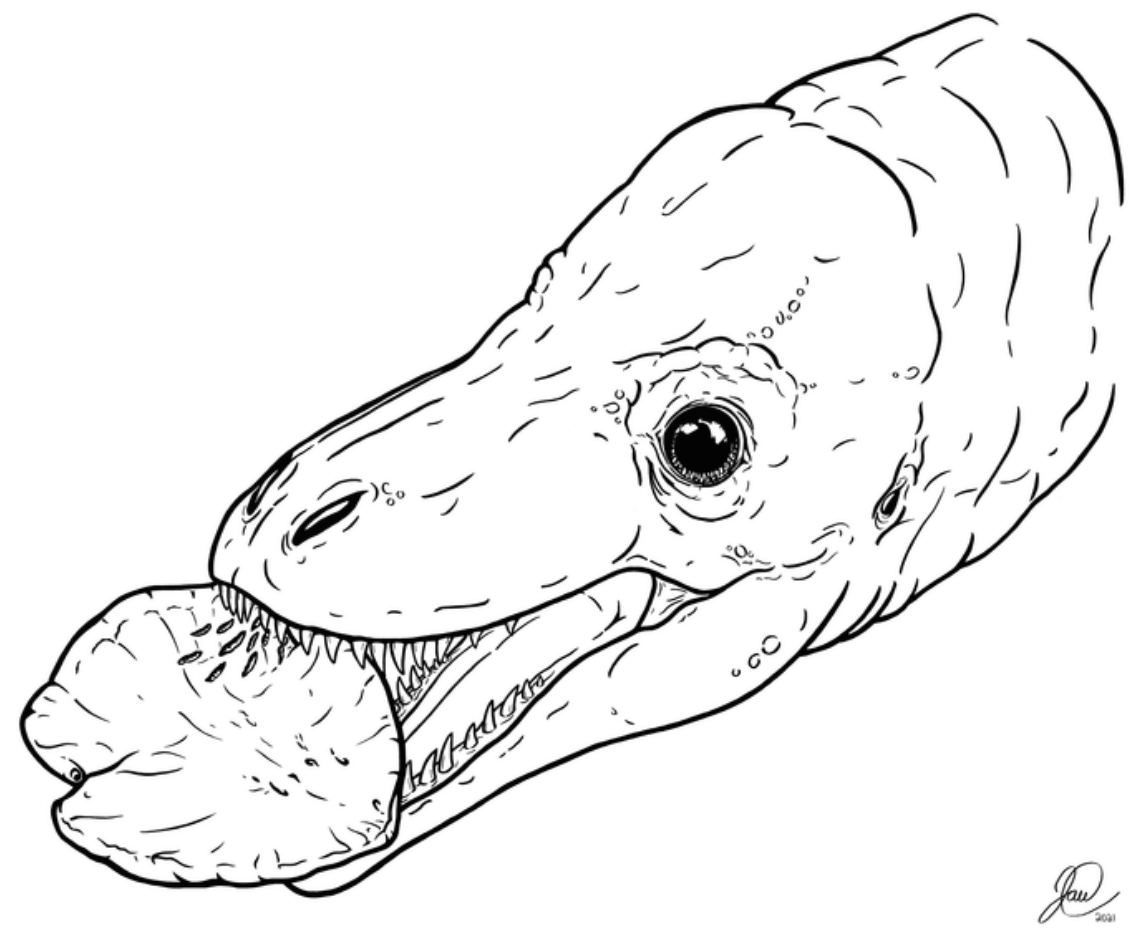




\section{Table $\mathbf{1}$ (on next page)}

Linear measurements of the 13 tooth marks on TMP 2018.012.0123.

See Fig. 1B for mark numbers. 
Table 1: Linear measurements (longest axis) of the 13 tooth marks on TMP 2018.012.0123. See Figure 1B for mark numbers.

3

4

5

\begin{tabular}{|c|cc|rr|}
\hline Mark & Row & Column & Length $(\mathbf{m m})$ & Width $(\mathbf{m m})$ \\
\hline 1 & i & b & 7.8 & 2.7 \\
2 & i & c & 6.5 & 2.1 \\
3 & ii & a & 7.9 & 2.4 \\
4 & ii & b & 10.5 & 3.3 \\
5 & ii & c & 6.6 & 2.3 \\
6 & iii & a & 7.8 & 2.1 \\
7 & iii & b & 8.5 & 2.3 \\
8 & iii & c & 4.7 & 1.6 \\
9 & iv & b & 5.8 & 1.8 \\
10 & iv & c & 5.1 & 1.6 \\
11 & v? & c? & 2.7 & 1.6 \\
12 & vi & a? & 5.0 & 2.3 \\
13 & vi & b? & 4.0 & 2.3 \\
\hline Mean & & & 6.4 & 2.2 \\
\hline
\end{tabular}




\section{Table 2 (on next page)}

Spacing between successive tooth marks by both row ( $i$, ii, etc.) and column ( $a$, b, etc.) on TMP 2018.012.0123.

See Fig. $2 \mathrm{C}$ for row and column designation. 
1 Table 2: Spacing between successive tooth marks by both rows (i, ii, etc.) and columns (a, b, 2 etc.) on TMP 2018.012.0123, see Figure 2C.

3

\begin{tabular}{|ll|r|}
\hline Alignment & Marks & \multicolumn{2}{c|}{$\begin{array}{c}\text { Distance } \\
\text { (mm) }\end{array}$} \\
\hline Rows & & 8.8 \\
i & 1,2 & 8.6 \\
ii & 3,4 & 6.8 \\
ii & 4,5 & 6.6 \\
iii & 6,7 & 4.9 \\
iii & 7,8 & 6.4 \\
\hline & 9,10 & 7.0 \\
\hline Columns & Mean & \\
a & 3,6 & 6.1 \\
b & 1,4 & 7.4 \\
b & 4,7 & 4.9 \\
b & 7,9 & 4.2 \\
c & 2,5 & 4.0 \\
c & 5,8 & 5.5 \\
c & 8,10 & 5.2 \\
\hline & Mean & 5.3 \\
\hline
\end{tabular}

4 


\section{Table 3 (on next page)}

Spacing between successive tooth positions (or alveoli) in tooth rows across specimens of several potential tracemakers. 
1 Table 3: Spacing between successive tooth positions (or alveoli) in tooth rows across specimens 2 of several potential tracemakers.

3

\begin{tabular}{|c|c|c|c|c|c|c|c|c|c|c|c|c|c|c|c|c|c|c|c|c|}
\hline Taxon & Specimen & Element & & & & & & & & & & & & & & & & & $\begin{array}{l}\text { Mean } \\
(\mathrm{mm})\end{array}$ & Count (n) \\
\hline $\begin{array}{l}\text { Gorgosaurus } \\
\text { libratus }- \text { juv. }\end{array}$ & $\begin{array}{l}\text { TMP } \\
1994.012 .0155 \\
\end{array}$ & R. Dent. & 12.6 & 12.3 & 12.9 & 12.8 & 11.9 & 12.8 & 12.1 & 12.4 & 12.7 & 10.3 & 9.6 & & & & & & 12.0 & 11 \\
\hline $\begin{array}{l}\text { Gorgosaurus } \\
\text { libratus - juv. }\end{array}$ & $\begin{array}{l}\text { TMP } \\
1994.012 .0155\end{array}$ & L. Dent. & 11.4 & 12.5 & 14.2 & 12 & 12.9 & 12 & 12.1 & 11.2 & 10.7 & 10.1 & & & & & & & 11.9 & 10 \\
\hline $\begin{array}{l}\text { Gorgosaurus } \\
\text { libratus - juv. }\end{array}$ & $\begin{array}{l}\text { TMP } \\
1990.081 .0006 \\
\end{array}$ & R. Dent. & 10.7 & 10.5 & 11 & 11.6 & 11 & 10 & & & & & & & & & & & 10.8 & 6 \\
\hline $\begin{array}{l}\text { Saurornitholestes } \\
\text { langstoni }\end{array}$ & $\begin{array}{l}\text { TMP } \\
1988.121 .0039 \\
\end{array}$ & L. Dent. & 5.8 & 4.9 & 5 & 5.6 & 6.4 & 5.1 & 5.2 & 4.9 & 5 & 5.9 & 5.9 & 4.9 & 4.3 & 4.4 & & & 5.2 & 14 \\
\hline $\begin{array}{l}\text { Saurornitholestes } \\
\text { langstoni }\end{array}$ & $\begin{array}{l}\text { TMP } \\
1991.036 .0112 \\
\end{array}$ & L. Dent. & 7.2 & 7.6 & 7.9 & 7.8 & & & & & & & & & & & & & 7.6 & 4 \\
\hline $\begin{array}{l}\text { Stenonychosaurus } \\
\text { inequalis }\end{array}$ & $\begin{array}{l}\text { TMP } \\
1982.016 .0138 \\
\end{array}$ & L. Dent. & 3.6 & 3.6 & 3.6 & 3.1 & 3.4 & 3.1 & & & & & & & & & & & 3.4 & 6 \\
\hline $\begin{array}{l}\text { Dromaeosaurus } \\
\text { albertensis }\end{array}$ & $\begin{array}{l}\text { TMP } \\
1984.008 .0001 \\
\end{array}$ & L. Dent. & 6.3 & 8.3 & 8.2 & 8.1 & 7.9 & 7.8 & 7.3 & 7.6 & 8.5 & & & & & & & & 7.8 & 9 \\
\hline $\begin{array}{l}\text { Dromaeosaurus } \\
\text { albertensis }\end{array}$ & $\begin{array}{l}\text { TMP } \\
1984.008 .0001\end{array}$ & R. Dent. & 6.7 & 6.6 & 8.3 & 8.5 & 8.7 & 8.6 & 8.2 & 7.6 & 7.4 & 6.6 & & & & & & & 7.7 & 10 \\
\hline
\end{tabular}

4

5

6 
Table 4 (on next page)

Results of Kolmogorov-Smirnov test (two sample), comparing the spacing between successive tooth positions (or alveoli) in TMP 2018.012.0123 with specimens of several potential tracemakers.

Bold values are significantly different, $\alpha<0.05$. 
1 Table 4: Results of Kolmogorov-Smirnov test (two sample), comparing the spacing between 2 successive tooth positions (or alveoli) in TMP 2018.012.0123 with specimens of several 3 potential tracemakers.

4

\begin{tabular}{|c|c|c|c|c|}
\hline & & & \multicolumn{2}{|c|}{ Toothmark Spacing } \\
\hline \multicolumn{3}{|c|}{ Potential Tracemakers Tooth Spacing } & Rows & Columns \\
\hline Specimen & Taxon & $\mathbf{N}$ & 6 & 7 \\
\hline TMP 1967.014.0039 & Stenonychosaurus inequalis & 21 & 0.0003242 & 0.0001179 \\
\hline TMP 1982.016.0138 & Stenonychosaurus inequalis & 6 & 0.004958 & 0.003125 \\
\hline TMP 1988.121.0039 & Saurornitholestes langstoni & 14 & 0.01525 & 0.8407 \\
\hline TMP 1991.036.0112 & Saurornitholestes langstoni & 4 & 0.181 & 0.0303 \\
\hline TMP 1984.008.0001 & Dromaeosaurus albertensis & 16 & 0.2989 & 0.001088 \\
\hline TMP 1990.081.0006 & Gorgosaurus libratus - Juvenile & 6 & 0.004958 & 0.003125 \\
\hline TMP 1994.012.0155 & Gorgosaurus libratus - Juvenile & 19 & 0.0001769 & 5.51E-05 \\
\hline
\end{tabular}
5 